\title{
Endoscopic biliary therapy in the era of bariatric surgery.
}

Harry Martin ${ }^{1}$, Tareq EL Menabawey ${ }^{1}$, Orla Webster ${ }^{2}$, Constantinos Parisinos ${ }^{1}$, Michael Chapman ${ }^{1}$, Stephen Pereira ${ }^{1}$, Gavin Johnson ${ }^{1}$ George Webster ${ }^{1}$.

Corresponding Author - George Webster, George.webster1@nhs.net, Division of GI Services Pancreatobiliary Medicine, University College Hospital, Ground Floor West, 250 Euston Road, London, NW1 2PG, UK

1. Division of GI Services Pancreatobiliary Medicine, University College Hospital, Ground Floor West, 250 Euston Road, London, NW1 2PG, UK

2. Bristol Medical School, University of Bristol, Beacon House, Queens Road, Bristol, UK, BS8 1QU, UK

Index words

Cholangiopancreatography, Endoscopic Retrograde

Bariatric Surgery

Gallstones

Bile Ducts

Choledocholithiasis

Word Count 2997

\begin{abstract}
There is an increasing demand and availability of bariatric surgery, with a range of procedures performed, some leading to altered upper gastrointestinal anatomy. The patient population undergoing bariatric surgery is also at increased risk of gallstones and biliary stone disease. Endoscopy (ie ERCP) is the cornerstone of management of biliary stone disease, but may be challenging after bariatric surgery. In this review the endoscopic, surgery-assisted, or percutaneous options that may be considered are discussed, based on the details of surgical anatomy and available expertise.
\end{abstract}

Key Bullet points as suggest in submission guidelines

1. Bariatric surgery is increasingly performed, and biliary disease is more common in this patient group. 
2. Dependant on bariatric procedure performed, conventional ERCP may be difficult or impossible.

3. Roux-en-Y gastric bypass presents particular challenges.

4. Per-oral (enteroscopy-assisted or EUS-assisted) or surgical (laparoscopic) ERCP may be effective, and antegrade percutaneous transhepatic approaches may be considered.

5. Therapeutic options should be carefully considered with a specialist MDM, mindful of surgical details and available expertise.

Contribution Statements

George Webster conceived the review and is guarantor for the text Harry Martin was lead author for preparing the text

Tareq El Menabawey and Constantinos Parisinos lead on section writing

Orla Webster designed and created the figures

Michael Chapman, Stephen Pereira and Gavin Johnson were involved in critical review and article editing

There was no funding for this article

There are no competing interests for this article

There are no other acknowledgements. 
The demand and provision of bariatric surgery continues to rise, with more than 5000 bariatric operations per year performed in the UK between 2012-2016, and more than 150,000 annually in the USA over a similar period $(1,2)$. As a result, there is a growing cohort of individuals with altered upper gastrointestinal (UGI) anatomy. Up to $50 \%$ of those undergoing bariatric surgery require a subsequent cholecystectomy for symptomatic gallstone disease(3-5). The European Association for the Study of the Liver (EASL) state that up to $16 \%$ of patients with gallstones may have concurrent bile duct stones(6).

Endoscopic retrograde cholangiopancreatography (ERCP) is the standard procedure for biliary intervention. Endoscopic access to the biliary tree is typically approached from the second part of the duodenum, to which endoscopic access may be challenging or impossible after certain types of bariatric surgery. Table 1 lists which approach is possible for each anatomical variant.

The focus of this review is to describe the post-surgical anatomy after the most common bariatric operations; discuss and evaluate methods to gain biliary access and approaches to therapy. We will briefly discuss non-bariatric post-surgical anatomy including Roux-en-Y hepaticojejunostomy and pancreaticoduodenectomy (Whipple's) as the principles of biliary access are similar.

\section{Common types of bariatric surgery}

\section{Gastric Band}

A silicone band is wrapped around the gastric cardia creating a small gastric pouch with a narrow outlet. The band tightness can be adjusted by inserting a needle into a reservoir embedded in the gastric wall. A duodenoscope can usually be passed through this band without difficulty. If there is any holdup the band can be released, or dilated up to $15 \mathrm{~mm}$. Conventional ERCP is rarely limited.

\section{Sleeve Gastrectomy}

This surgery creates a small residual gastric pouch in the form of a longitudinal portion of the stomach. The greater curve of the stomach is removed, leaving a residual portion containing the cardia, lesser curve and the pylorus. Biliary access via a conventional endoscopic approach should not be affected.

\section{Roux-en-Y Gastric Bypass}

Roux-en-Y gastric bypass (RYGB) surgery involves the exclusion of the majority of the stomach with a small residual gastric pouch remaining in continuity with the oesophagus. The residual pouch is anastomosed to a loop of small bowel, with a second anastomosis further down the small bowel (the 'Roux-en-Y' anastomosis), linking a further length of small bowel back to the duodenum. Of relevance to discussions below (and in contrast to a total gastrectomy) the excluded stomach remains in normal continuity with the duodenum. Access to the duodenum (and therefore the biliary tree) via a conventional per-oral endoscopic approach is not possible due to the disconnection of the proximal stomach from the rest of the excluded stomach. The alternative approaches to biliary access in this setting are discussed below.

\section{Therapeutic Interventions}

Adjunctive techniques used to gain biliary access post RYGB include those achieved through a conduit into the excluded stomach, via the Roux-en-Y anastomosis, or percutaneously. 


\section{Access via the excluded stomach}

\section{Laparoscopic assisted ERCP (LAP-ERCP)}

LAP-ERCP is performed as a combined procedure involving endoscopists and surgeons. The procedure is performed in an operating theatre with X-ray screening, an endoscopy stack, standard duodenoscope, and is carried out under general anaesthesia, with the patient in the supine position. On laparoscopy the stomach is identified and secured to the anterior abdominal wall using a $15-18 \mathrm{~mm}$ gastrotomy port and purse-string sutures. To aid insertion of the duodenoscope into the duodenum the surgeon should aim to insert the gastrotomy port as far from the pylorus as is feasible (to avoid sharp angulation of the duodenoscope to gain duodenal access). The duodenoscope is inserted via the port into the gastric remnant. Standard therapeutic ERCP technique is performed once in the duodenum. Post-procedure closure of the gastrostomy precludes subsequent removal of endoscopically placed stents without repeat surgery, due to the temporary nature of endoscopic access.

\section{Endoscopic ultrasound (EUS) directed transgastric ERCP (EDGE)}

Using EUS the excluded stomach is identified from either the remnant stomach or the jejunal limb beyond the gastro-jejunostomy. The excluded stomach is then accessed with an EUS needle, radiological contrast and dye-coloured water are injected to confirm the position and expand the excluded stomach. A 15 or $20 \mathrm{~mm}$ diameter lumen apposing metal stent (LAMS) is inserted over a wire, creating a conduit between the remnant stomach or jejunum and the excluded stomach. The proximal end of the LAMS can be secured in place using clips, endoscopic suturing or not at all. The LAMS can then be dilated if necessary.

This fistulous track through the LAMS can mature over 7-14 days or be used immediately. A per-orally inserted duodenoscope is passed through the LAMS into the excluded stomach to allow conventional duodenal access to the biliary tree. Once access to the ampulla is no longer required the LAMS is removed via gastroscopy and the defect closed using over-the-scope clips, endoscopic suturing, or left to close spontaneously. It may also be left in place for several weeks. Leaving the LAMS in place has not been shown to cause weight gain $(31,32)$.

\section{Access not via the excluded stomach}

\section{Enteroscopy Assisted ERCP}

RYGB and Roux-en-Y hepaticojejunostomy (e.g. following a liver transplant, pancreaticoduodenectomy or total gastrectomy) both involve the creation of a long afferent limb. Conventional duodenal access via the pylorus is not possible. In cases involving a long afferent limb balloon enteroscopy-assisted ERCP (BE-ERCP) can play a valuable role. Access to the biliary tree is via the small bowel afferent limb, which depending on the site of the Roux-en-Y anastomosis can be up to $200 \mathrm{~cm}$ long. It is vital that the endoscopist reviews the imaging and operation notes prior to intervention, ideally including discussion with the operating surgeon.

\section{Double balloon enteroscopy (DBE).}

DBE involves the use of a dedicated endoscope (up to $200 \mathrm{~cm}$ ) with a flexible polyurethane overtube. Latex balloons attached to the tip of the endoscope and overtube are filled and emptied with air. Coordinating sequential balloon inflation with alternating pushing and pulling manoeuvres allows deep enteral intubation into a long afferent limb, potentially providing access to the biliary tree. Particular consideration of ERCP accessories is needed, as equipment designed for use through the duodenoscope may be too short for the longer DBE scope, or too wide (most long DBE scopes use a $2.8 \mathrm{~mm}$ working channel). Shorter DBE 
scopes have been developed, with a $3.2 \mathrm{~mm}$ working channel, allowing the use of most conventional ERCP accessories. DBE intubation can be hampered by loop formation and surgical adhesions that limit manoeuvrability. Although the forward facing DBE scope makes navigating the afferent limb easier, the caudal approach and oblique angle of the papilla coupled with the absence of an elevator can make cannulation challenging(7).

\section{Single balloon enteroscopy assisted ERCP}

To achieve a stable position the endoscopist angles the tip, as is possible with any endoscope, or uses suction, instead of inflating and deflating a tip balloon (as for DBE). SBE has the benefit of requiring less time to set up and the angulated tip may make passing anastomoses easier, although there is debate regarding the extent of deep enteral intubation with SBE compared to DBE (8). As for DBE considerations regarding surgical anatomy and accessory use apply.

\section{Spiral assisted ERCP (SAE)}

Spiral enteroscopy involves the use of a rotating overtube to pleat the small bowel over the enteroscope facilitating deep intubation. In order to advance the enteroscope, "engagement" is necessary, such that the spiral part of the rotating overtube lightly grips the small intestine.

\section{Percutaneous approaches.}

Percutaneous transhepatic drainage (PTD) is a non-endoscopic antegrade approach to the biliary tree, usually performed by interventional radiologists. It may have a particular role where endoscopic approaches have either failed or are deemed not possible. Under ultrasound and fluoroscopic guidance the intrahepatic biliary tree is punctured with a needle, allowing a wire and subsequent drains to be inserted. This may then allow direct intraductal visualisation for stone fragmentation or stricture assessment(9). Recently developed shorter cholangioscopes (including the 10.5F Spyglass Discover cholangioscope (Boston Scientific Inc)) may be inserted down a $12 \mathrm{~F}$ percutaneous transhepatic sheath. PTD may be challenging in the setting of non-dilated intrahepatic ducts or multiple intrahepatic strictures. It may be contraindicated by large volume ascites or an unresolvable coagulopathy. Subsequent cholangioscopy may be challenging where sharp angulation is required to access intrahepatic ducts of interest, but may be straightforward if pathology (stone or stricture) is present along the line of the previous drain or in the extrahepatic biliary tree, allowing a clear antegrade approach.

\section{Discussion}

Until the last 15 years the most frequently encountered surgically altered upper GI anatomy was the Billroth 2 partial gastrectomy. As surgery for benign ulcers has become infrequent, altered anatomy related to bariatric surgery has become increasingly common in the setting of bile duct stone disease. EASL acknowledges that complications of gallstones following bariatric surgery may be significant but does not routinely recommend prophylactic cholecystectomy, for asymptomatic gallstones, at the time of bariatric surgery(6).

In individuals with common bile duct stones and an intact gallbladder, surgery (cholecystectomy and bile duct exploration) may be the preferred option. Although laparoscopic bile duct exploration and stone clearance has been shown to be effective and safe in expert hands $(10,11)$ complications may be increased in patients with multiple comorbidities and this service is inconsistently available. 
BE-ERCP is commonly the first line approach to biliary access in those with altered UGI anatomy(12). As a single operator procedure the logistics of organising this are simpler than LAP-ERCP. However, LAP-ERCP provides a higher therapeutic success rate than BEERCP $(13,14)$. In separate meta-analyses De Ponte Neto (2018) showed a native cannulation rate of $95.7 \%$ vs $82.2 \%$ for LAP-ERCP vs DBE-ERCP and $95.7 \%$ vs $62.2 \%$ compared to SBEERCP(15). Ayoub (2020) demonstrated a pooled cannulation rate of $97.8 \%$ vs $73.0 \%$ for LAPERCP vs BE-ERCP(16). The LAP-ERCP complication rate was approximately $11 \%$ and $12 \%$ higher in de Ponte-Neto's and Ayoub's analysis respectively. The main complications of infection and bleeding are attributed to the laparoscopic portion of the procedure. Direct ERCP related complications appeared similar between LAP-ERCP and BE-ERCP $(13,16)$. The most common ERCP related complication is pancreatitis, which is not a risk where the ampulla is not identified and therefore cannulation not attempted (a scenario more commonly seen for BE-ERCP).

A recent retrospective study comparing LAP-ERCP and BE-ERCP in those with Roux-en-Y anatomy post bariatric surgery found similar success rates $(87.2 \%$ vs $72.5 \%)$ and complication rates $(28 \%$ vs $18 \%)$. However, success rate significantly improved in both modalities from the first quintile to the last (50 to $75 \%$ for BE-ERCP and $88 \%$ to $100 \%$ for LAP-ERCP suggesting that endoscopist experience has a significant impact on success(17).

The technical and clinical success of LAP-ERCP, BE-ERCP and percutaneous approaches to the management of biliary disease post-altered upper GI tract anatomy is hampered by the fact that most data are from retrospective, single centre and single operator cohort studies. Most reports are non-randomised, and significant heterogeneity exists in the reported success rates between researchers. The largest prospective multi-operator, multicentre study by Shimatani involved 3 tertiary centres and 2 community hospitals in Japan with short type DBEERCP on 311 patients including 203 Roux-en-Y reconstructions. They demonstrated very high cannulation rates of $96.4 \%$ and therapeutic success in $97.9 \%$ in those requiring intervention(18). All procedures were performed by specialists in DBE. A 2017 meta-analysis of DBE-ERCP comprising 301 patients with a variety of post-surgical anatomy (Roux en $Y$ for liver transplant, RYGB and pancreaticoduodenectomy) reported a pooled cannulation rate of $79.92 \%$ with a $63.55 \%$ probability of therapeutic success(19). The length of the limb in Rouxen-Y seems to be associated with cannulation success. The length of the small bowel loop is of fundamental importance, with successful cannulation rates for DBE-ERCP in RYGB of $67 \%$ for long DBE, and $88-97 \%$ for short DBE(18,20-22). De Koning reported a cannulation rate of $58 \%$ in long afferent limb RYGB vs $80 \%$ in short limb. In the setting of BE-ERCP 'failed cannulation' (which by definition leads to failed therapy) largely results from failure to reach the papilla. Nevertheless, even where the papilla is reached therapy may be limited by endoscope orientation and availability of ERCP accessories suitable for the long balloon enteroscopes. Improved technical success with short SBE v long SBE (92\% vs $84 \%$ ) likely reflects the fact that, if the papilla can be reached, the short SBE $(152 \mathrm{~cm})$ used in this study has a $3.2 \mathrm{~mm}$ working channel (compared to the long SBE's $2.8 \mathrm{~mm}$ channel) allowing conventional ERCP accessories to be used(23). Yamauchi et al reported the use of peroral direct cholangioscopy via a short SBE in 11 patients who had difficult bile duct stones following RYGB. Stone clearance was achieved in $86 \%$ in the first session and $100 \%$ by the second session(24).

Luminal perforation, including of the surgical anastomosis (bilioenteric and enteroenteric), is more common for BE-ERCP than conventional ERCP (25). As an unusual complication, the use of overtubes to stabilise enteroscope insertion may rarely lead to a 'closed loop' and subsequent barotrauma due to increased intraluminal pressure. This may be associated with a retroperitoneal leak post-sphincterotomy, gallbladder perforation or dehiscence of the liver capsule $(25,26)$. Shimatani's large prospective multicentre DBE-ERCP study reported an adverse event rate of $10.6 \%(18)$. 
De Koning showed no difference between SBE and DBE-ERCP (success rate of $75 \%$ and $73 \%$ respectively) with a similar risk of adverse events (8\% vs $10 \%)(26)$ Shah et al conducted a retrospective multicentre comparison of DBE, SBE and spiral assisted ERCP in 129 long limb surgical bypass patients and found no significant difference in ERCP success rates $(74 \%$ vs $69 \%$ vs $72 \%$ respectively)(20).

A percutaneous transhepatic approach may allow biliary access where endoscopic access is difficult or impossible, and can be used as the primary approach. Whilst small stones may be pushed out of the biliary tree from an antegrade position using balloons (often following primary balloon sphincteroplasty), additional techniques may often be necessary. 10F (3.5mm diameter) single operator cholangioscopes, including the recently developed Spyglass Discover cholangioscope (Boston Scientific, USA) may be inserted over a previously formed percutaneous transhepatic tract, allowing stone fragmentation or stricture assessment under direct vision. In our early experience of percutaneous transhepatic cholangioscopy (PTCS) stone clearance was achieved in all 5 patients with no complications (27). However, PTCS is labour and resource intensive, requiring interventional radiology and necessitates several stages including i. initial PTD, ii. tract dilation to $12 \mathrm{~F}$, ii. tract maturation for 10 days with drain in-situ and iv. PTCS itself. Each stage carries its own complication risk with comparable therapeutic outcomes to the other modalities described above. A retrospective analysis of 364 patients undergoing PTCS using early generation cholangioscopes showed that procedure related complications occurred during PTD insertion in 12.9\%, tract dilation in $12.8 \%$ and tract maturation in $6.9 \%$. The incidence of complications of cholangioscopy itself was $6.7 \%(9)$, similar to the rates seen with conventional retrograde cholangioscopy (28). In a small study Tsutsymi and colleagues addressed the question of antegrade cholangioscopy (ie PTCS) ( $\mathrm{n}$ $=8)$ versus retrograde per oral direct cholangioscopy (PDCS) via short DBE $(n=32)$ in the treatment of stones in patients post hepaticojejunostomy. Success was $100 \%$ in the PTCS group and $91 \%$ in the PDCS group(29). The 3 patients who failed PDCS underwent subsequent PTCS successfully. The short DBE group had significantly lower adverse events when compared with the PTCS (10\% vs $45 \%)$ but stone clearance was achieved faster with PTCS than short DBE-PDCS (10 days vs 35 days). There was no significant difference in stone free status at 1, 2 and 3 year follow up (100\%, 73\%, and $64 \%$ for PTCS and $85 \%, 65 \%$, and 59\% for PDCS, respectively). The 2018 updated Tokyo guidelines recommend the use of device assisted ERCP for treatment of stones in patients with altered anatomy but recognises that percutaneous approaches are a good alternative where expertise in device assisted ERCP is not available(30).

Endoscopic ultrasound-directed trans-gastric ERCP (EDGE) is a recently described technique with limited data to date outside of highly specialised centres. Therapeutic success appears to be consistently above $90 \%$ with complications between 10 and $24 \%(31-33)$. Published studies are small and mastery of the technique appears to be reached after 25-35 procedures(31). A multicentre retrospective review comparing LAP-ERCP and EDGE showed that EDGE was technically non inferior, with similar levels of adverse effects (both minor or major). EDGE procedures were of shorter duration (73 minutes vs 184 minutes) and patients had a shorter hospital stay ( 0.8 days vs 2.65 days)(32). EDGE also appears to be a more cost effective modality(34). A retrospective multi-centred review of 30 patients in each arm of EDGE vs BE-ERCP found EDGE to have a statistically significantly higher success rate $(100 \%$ vs $60 \%, p<.001$ ), shorter procedure time (49.8 vs 90.7 minutes $\mathrm{p}<.001)$, shorter length of stay ( 1 vs 10.5 days $p=.02$ ) with similar adverse event rates (10\% vs $6.7 \%)(33)$. Early repeat endoscopic access to duodenum may be necessary following initial ERCP, whether to make further attempts at biliary access or therapy; removal of a prophylactic pancreatic stent; or treat a post-sphincterotomy bleed (which may occur in up to $2 \%$ of cases). Access to the duodenum is lost as soon as LAP-ERCP is finished (as the gastrostomy is closed). An advantage of EDGE may be that the LAMS may be left in place to allow future endoscopic access as needed. 
Table 2 lists the key studies and outcomes.

\section{Conclusions}

Biliary intervention may be complex in those with altered UGI anatomy. Increasing therapeutic options are available, both endoscopic and percutaneous, but a clear understanding of previous surgery is essential. Well controlled studies directly comparing the different options remain limited, and careful decision-making needs to balance available expertise with anatomical considerations and patient wishes. Available data suggest that in those with an intact, excluded stomach (ie RYGB) a technique allowing a conventional ERCP approach (ie LAP-ERCP or EDGE) allows the best chance of technical therapeutic success. BE-ERCP may be a good alternative, particularly where a short enteroscope allows the use of a full range of accessories. Percutaneous-transhepatic approaches overcome difficult UGI anatomy, and may allow stone therapy and stricture assessment using cholangioscopy. To optimise decision-making and patient care, individual case discussion within a specialist pancreaticobiliary multidisciplinary team may be invaluable.

Table 1. Methods of biliary access after upper gastrointestinal surgery.

\begin{tabular}{|l|l|l|}
\hline Previous Surgery & $\begin{array}{l}\text { Bariatric } \\
\text { Surgery }\end{array}$ & $\begin{array}{l}\text { Primary approaches for } \\
\text { biliary access }\end{array}$ \\
\hline Gastric Band & Yes & Conventional ERCP \\
\hline Sleeve Gastrectomy & Yes & Conventional ERCP \\
\hline Roux-en-Y Gastric Bypass & Yes & $\begin{array}{l}\text { LAP-ERCP } \\
\text { EDGE } \\
\text { BE-ERCP } \\
\text { PTD +/- cholangioscopy }\end{array}$ \\
\hline Billroth I partial gastrectomy & No & $\begin{array}{l}\text { Conventional ERCP } \\
\text { Billroth 2 partial gastrectomy }\end{array}$ \\
\hline & No & $\begin{array}{l}\text { Conventional ERCP (via } \\
\text { afferent limb) } \\
\text { BE-ERCP } \\
\text { PTD +/- cholangioscopy }\end{array}$ \\
\hline
\end{tabular}




\begin{tabular}{|l|l|l|}
\hline & & \\
\hline $\begin{array}{l}\text { Total -gastrectomy with Roux-en-Y } \\
\text { anastomosis }\end{array}$ & No & $\begin{array}{l}\text { BE-ERCP } \\
\text { PTD +/- cholangioscopy }\end{array}$ \\
\hline Pancreaticoduodenectomy (Whipple) & No & $\begin{array}{l}\text { BE-ERCP } \\
\text { PTD +/- cholangioscopy }\end{array}$ \\
\hline
\end{tabular}

Table 2. Characteristics of key studies

\begin{tabular}{|l|l|l|l|l|l|}
\hline Procedure & Study & $\begin{array}{l}\text { Papilla } \\
\text { Identification } \\
(\mathrm{n}(\%))\end{array}$ & $\begin{array}{l}\text { Papilla } \\
\text { cannulation } \\
(\mathrm{n}(\%))\end{array}$ & $\begin{array}{l}\text { Therapeutic } \\
\text { success } \\
(\mathrm{n}(\%))\end{array}$ & $\begin{array}{l}\text { Complications } \\
(\mathrm{n}(\%))\end{array}$ \\
\hline LAP ERCP & $\begin{array}{l}\text { Tonnesen } \\
2020(35)\end{array}$ & $38 / 39(97.4 \%)$ & $37 / 39(94.9 \%)$ & $34 / 39(87.1 \%)$ & $11 / 39(28.2 \%)$ \\
\cline { 2 - 6 } & $\begin{array}{l}\text { CH Lim } \\
2017(36)\end{array}$ & $50 / 50(100 \%)$ & $50 / 50(100 \%)$ & Not available & $3 / 50(6 \%)$ \\
\cline { 2 - 6 } & $\begin{array}{l}\text { Abbas } \\
2018(37)\end{array}$ & $\begin{array}{l}573 / 579 \\
(99.0 \%)\end{array}$ & $567 / 579(97.2 \%)$ & $567 / 579(97.2 \%)$ & $106 / 579(18.3 \%)$ \\
\hline $\begin{array}{l}\text { Single } \\
\text { Balloon } \\
\text { Enteroscopy } \\
\text { assisted } \\
\text { ERCP }\end{array}$ & $\begin{array}{l}\text { Trindade } \\
2015(38)\end{array}$ & $49 / 56(87.5 \%)$ & $44 / 56(78.6 \%)$ & $40 / 56(71.4 \%)$ & $3 / 56(5.4 \%)$ \\
\hline
\end{tabular}




\begin{tabular}{|c|c|c|c|c|c|}
\hline & $\begin{array}{l}\text { Ishii } 2016 \\
\text { (39) }\end{array}$ & 97/107 (90.7\%) & 57/107 53.3\%) & Not available & $8 / 97(8.2 \%)$ \\
\hline \multirow{3}{*}{$\begin{array}{l}\text { Double } \\
\text { Balloon } \\
\text { Enteroscopy } \\
\text { assisted } \\
\text { ERCP }\end{array}$} & $\begin{array}{l}\text { Kashani } \\
2018(40)\end{array}$ & \begin{tabular}{|l|}
$121 / 129$ \\
$(93.8 \%)$
\end{tabular} & $116 / 129(89.9 \%)$ & $114 / 129(88.4 \%)$ & $13 / 129(10.1 \%)$ \\
\hline & $\begin{array}{l}\text { Choi } 2013 \\
(41)\end{array}$ & 25/32 (78.1\%) & 20/32 (62.5\%) & $18 / 32(56.3 \%)$ & $1 / 32(3.1 \%)$ \\
\hline & $\begin{array}{l}\text { Shimatani } \\
2016 \\
(18)\end{array}$ & \begin{tabular}{|l|}
$304 / 311$ \\
$(97.7 \%)$
\end{tabular} & 293/311 (94.\%) & 287/311 (92.3\%) & $33 / 311(10.6 \%)$ \\
\hline \multirow{2}{*}{$\begin{array}{l}\text { Spiral } \\
\text { Enteroscopy } \\
\text { assisted } \\
\text { ERCP }\end{array}$} & $\begin{array}{l}\text { Ali } 2018 \\
\text { (42) }\end{array}$ & $30 / 35(85.7 \%)$ & 28/30 (93.3\%) & $28 / 30(93.3 \%)$ & Not available \\
\hline & $\begin{array}{l}\text { Zouhairi } \\
2015 \text { (43) }\end{array}$ & 32/42 (76.2\%) & 26/42 (61.9\%) & 24/42 (57.1\%) & 3/42 (7.1\%) \\
\hline \multirow[t]{2}{*}{ EDGE } & Kedia (32) & $28 / 29(96.6 \%)$ & 28/29 (96.6\%) & $28 / 29$ (96.6\%) & $7 / 29$ (24.1\%) \\
\hline & \begin{tabular}{|l} 
Bukhari \\
$2018(33)$
\end{tabular} & $30 / 30(100 \%)$ & $30 / 30(100 \%)$ & $30 / 30(100 \%)$ & $3 / 30(10 \%)$ \\
\hline $\begin{array}{l}\text { Percutaneous } \\
\text { Cholangiosco } \\
\text { py }\end{array}$ & Oh 2016 (9) & \multicolumn{4}{|c|}{$\begin{array}{l}364 \text { patients had } 1903 \text { procedures across the } 4 \text { stages of the } \\
\text { procedure. } \\
\text { There were } 165 \text { complications across these procedures. }\end{array}$} \\
\hline
\end{tabular}




\section{References}

1. Bariatric-Surgery-Clinical-Outcomes-Publication-for-2015-16.pdf [Internet]. [cited 2019 Sep 20]. Available from: http://www.bomss.org.uk/wpcontent/uploads/2017/03/Bariatric-Surgery-Clinical-Outcomes-Publication-for-2015-16.pdf

2. American Society for Metabolic and Bariatric Surgery. Estimate of Bariatric Surgery Numbers.

3. O'brien P e. A rational approach to cholelithiasis in bariatric surgery: Its application to the laparoscopically placed adjustable gastric band. Arch Surg. 2003 Aug 1;138(8):908.

4. Deitel M, Petrov I. Incidence of symptomatic gallstones after bariatric operations. Surg Gynecol Obstet. 1987 Jun;164(6):549-52.

5. Elton E, Hanson BL, Qaseem T, Howell DA. Diagnostic and therapeutic ERCP using an enteroscope and a pediatric colonoscope in long-limb surgical bypass patients. Gastrointest Endosc. 1998 Jan;47(1):62-7.

6. EASL Clinical Practice Guidelines on the prevention, diagnosis and treatment of gallstones. Journal of Hepatology. 2016 Jul;65(1):146-81.

7. Itokawa F, Itoi T, Ishii K, Sofuni A, Moriyasu F. Single- and double-balloon enteroscopy-assisted endoscopic retrograde cholangiopancreatography in patients with Roux-en-Y plus hepaticojejunostomy anastomosis and Whipple resection. Dig Endosc. 2014 Apr;26 Suppl 2:136-43.

8. Wadhwa V, Sethi S, Tewani S, Garg SK, Pleskow DK, Chuttani R, et al. A metaanalysis on efficacy and safety: single-balloon vs. double-balloon enteroscopy. Gastroenterol Rep (Oxf). 2015 May;3(2):148-55.

9. Oh H-C. Percutaneous Transhepatic Cholangioscopy in Bilioenteric Anastomosis Stricture. Clin Endosc. 2016 Nov;49(6):530-2.

10. Strömberg C, Nilsson M, Leijonmarck C-E. Stone clearance and risk factors for failure in laparoscopic transcystic exploration of the common bile duct. Surg Endosc. 2008 May;22(5):1194-9.

11. Topal B, Aerts R, Penninckx F. Laparoscopic common bile duct stone clearance with flexible choledochoscopy. Surg Endosc. 2007 Dec;21(12):2317-21.

12. Nakai Y, Kogure H, Yamada A, Isayama H, Koike K. Endoscopic management of bile duct stones in patients with surgically altered anatomy. Dig Endosc. 2018 Apr;30 Suppl $1: 67-74$.

13. Krutsri C, Kida M, Yamauchi H, Iwai T, Imaizumi H, Koizumi W. Current status of endoscopic retrograde cholangiopancreatography in patients with surgically altered anatomy. World J Gastroenterol. 2019 Jul 14;25(26):3313-33.

14. Aiolfi A, Asti E, Rausa E, Bernardi D, Bonitta G, Bonavina L. Trans-Gastric ERCP After Roux-en-Y Gastric Bypass: Systematic Review and Meta-Analysis. Obes Surg. 2018;28(9):2836-43.

15. da Ponte-Neto AM, Bernardo WM, de A Coutinho LM, Josino IR, Brunaldi VO, Moura DTH, et al. Comparison between Enteroscopy-Based and Laparoscopy-Assisted ERCP for 
Accessing the Biliary Tree in Patients with Roux-en-Y Gastric Bypass: Systematic Review and Meta-analysis. Obes Surg. 2018;28(12):4064-76.

16. Ayoub F, Brar TS, Banerjee D, Abbas AM, Wang Y, Yang D, et al. Laparoscopyassisted versus enteroscopy-assisted endoscopic retrograde cholangiopancreatography $(E R C P)$ in Roux-en-Y gastric bypass: a meta-analysis. Endosc Int Open. 2020 Mar;8(3):E423-36.

17. Tønnesen CJ, Young J, Glomsaker T, Mala T, Løberg M, Bretthauer M, et al. Laparoscopy-assisted versus balloon enteroscopy-assisted ERCP after Roux-en-Y gastric bypass. Endoscopy. 2020 Aug;52(8):654-61.

18. Shimatani M, Hatanaka H, Kogure H, Tsutsumi K, Kawashima H, Hanada K, et al. Diagnostic and Therapeutic Endoscopic Retrograde Cholangiography Using a Short-Type Double-Balloon Endoscope in Patients With Altered Gastrointestinal Anatomy: A Multicenter Prospective Study in Japan. Am J Gastroenterol. 2016 Dec;111(12):1750-8.

19. Shao X-D, Qi X-S, Guo X-Z. Endoscopic retrograde cholangiopancreatography with double balloon enteroscope in patients with altered gastrointestinal anatomy: A metaanalysis. Saudi J Gastroenterol. 2017 Jun;23(3):150-60.

20. Shah RJ, Smolkin M, Yen R, Ross A, Kozarek RA, Howell DA, et al. A multicenter, U.S. experience of single-balloon, double-balloon, and rotational overtube-assisted enteroscopy ERCP in patients with surgically altered pancreaticobiliary anatomy (with video). Gastrointest Endosc. 2013 Apr;77(4):593-600.

21. Siddiqui AA, Chaaya A, Shelton C, Marmion J, Kowalski TE, Loren DE, et al. Utility of the short double-balloon enteroscope to perform pancreaticobiliary interventions in patients with surgically altered anatomy in a US multicenter study. Dig Dis Sci. 2013 Mar;58(3):85864.

22. Osoegawa T, Motomura Y, Akahoshi K, Higuchi N, Tanaka Y, Hisano T, et al. Improved techniques for double-balloon-enteroscopy-assisted endoscopic retrograde cholangiopancreatography. World J Gastroenterol. 2012 Dec 14;18(46):6843-9.

23. Iwai T, Kida M, Yamauchi H, Imaizumi H, Koizumi W. Short-type and conventional single-balloon enteroscopes for endoscopic retrograde cholangiopancreatography in patients with surgically altered anatomy: single-center experience. Dig Endosc. 2014 Apr;26 Suppl 2:156-63.

24. Yamauchi H, Kida M, Okuwaki K, Miyazawa S, Matsumoto T, Uehara K, et al. Therapeutic peroral direct cholangioscopy using a single balloon enteroscope in patients with Roux-en-Y anastomosis (with videos). Surg Endosc. 2018 Jan;32(1):498-506.

25. Moreels TG. Endoscopic retrograde cholangiopancreatography in patients with altered anatomy: How to deal with the challenges? World J Gastrointest Endosc. 2014 Aug $16 ; 6(8): 345-51$.

26. De Koning M, Moreels TG. Comparison of double-balloon and single-balloon enteroscope for therapeutic endoscopic retrograde cholangiography after Roux-en-Y small bowel surgery. BMC Gastroenterol. 2016 Aug 22;16(1):98.

27. Goodchild G, Potts J, Burr N, Keane MG, Chapman MH, Johnson GJ, et al. ADTH-05 Percutaneous transhepatic cholangioscopy in the treatment of biliary ductal stones. In: Endoscopy [Internet]. BMJ Publishing Group Ltd and British Society of Gastroenterology; 
2018 [cited 2020 Nov 16]. p. A9.2-A10. Available from: https://gut.bmj.com/lookup/doi/10.1136/gutjnl-2018-BSGAbstracts.17

28. Kalaitzakis E, Webster GJ, Oppong KW, Kallis Y, Vlavianos P, Huggett M, et al. Diagnostic and therapeutic utility of single-operator peroral cholangioscopy for indeterminate biliary lesions and bile duct stones. Eur J Gastroenterol Hepatol. 2012 Jun;24(6):656-64.

29. Tsutsumi K, Kato H, Yabe S, Mizukawa S, Seki H, Akimoto Y, et al. A comparative evaluation of treatment methods for bile duct stones after hepaticojejunostomy between percutaneous transhepatic cholangioscopy and peroral, short double-balloon enteroscopy. Therap Adv Gastroenterol. 2017 Jan;10(1):54-67.

30. Mukai S, Itoi T, Baron TH, Takada T, Strasberg SM, Pitt HA, et al. Indications and techniques of biliary drainage for acute cholangitis in updated Tokyo Guidelines 2018. J Hepatobiliary Pancreat Sci. 2017 Oct;24(10):537-49.

31. Tyberg A, Kedia P, Tawadros A, Tarnasky PR, Gaidhane M, Nieto J, et al. EUSDirected Transgastric Endoscopic Retrograde Cholangiopancreatography (EDGE): The First Learning Curve. J Clin Gastroenterol. 2020 Jul;54(6):569-72.

32. Kedia P, Tarnasky PR, Nieto J, Steele SL, Siddiqui A, Xu M-M, et al. EUS-directed Transgastric ERCP (EDGE) Versus Laparoscopy-assisted ERCP (LA-ERCP) for Roux-en-Y Gastric Bypass (RYGB) Anatomy: A Multicenter Early Comparative Experience of Clinical Outcomes. J Clin Gastroenterol. 2019;53(4):304-8.

33. Bukhari M, Kowalski T, Nieto J, Kunda R, Ahuja NK, Irani S, et al. An international, multicenter, comparative trial of EUS-guided gastrogastrostomy-assisted ERCP versus enteroscopy-assisted ERCP in patients with Roux-en-Y gastric bypass anatomy. Gastrointest Endosc. 2018 Sep;88(3):486-94.

34. James HJ, James TW, Wheeler SB, Spencer JC, Baron TH. Cost-effectiveness of endoscopic ultrasound-directed transgastric ERCP compared with device-assisted and laparoscopic-assisted ERCP in patients with Roux-en-Y anatomy. Endoscopy. 2019;51(11):1051-8.

35. Tønnesen CJ, Young J, Glomsaker T, Mala T, Løberg M, Bretthauer M, et al. Laparoscopy-assisted versus balloon enteroscopy-assisted ERCP after Roux-en-Y gastric bypass. Endoscopy. 2020 Aug;52(8):654-61.

36. Lim CH, Jahansouz C, Freeman ML, Leslie DB, Ikramuddin S, Amateau SK. Outcomes of Endoscopic Retrograde Cholangiopancreatography (ERCP) and Sphincterotomy for Suspected Sphincter of Oddi Dysfunction (SOD) Post Roux-En-Y Gastric Bypass. Obes Surg. 2017;27(10):2656-62.

37. Abbas AM, Strong AT, Diehl DL, Brauer BC, Lee IH, Burbridge R, et al. Multicenter evaluation of the clinical utility of laparoscopy-assisted ERCP in patients with Roux-en-Y gastric bypass. Gastrointest Endosc. 2018 Apr;87(4):1031-9.

38. Trindade AJ, Mella JM, Slattery E, Cohen J, Dickstein J, Garud SS, et al. Use of a cap in single-balloon enteroscopy-assisted endoscopic retrograde cholangiography. Endoscopy. 2015 May;47(5):453-6.

39. Ishii K, Itoi T, Tonozuka R, Itokawa F, Sofuni A, Tsuchiya T, et al. Balloon enteroscopy-assisted ERCP in patients with Roux-en-Y gastrectomy and intact papillae (with videos). Gastrointest Endosc. 2016 Feb;83(2):377-386.e6. 
40. Kashani A, Abboud G, Lo SK, Jamil LH. Double balloon enteroscopy-assisted endoscopic retrograde cholangiopancreatography in Roux-en-Y gastric bypass anatomy: expert vs. novice experience. Endosc Int Open. 2018 Jul;6(7):E885-91.

41. Choi EK, Chiorean MV, Coté GA, El Hajj II, El Hajj I, Ballard D, et al. ERCP via gastrostomy vs. double balloon enteroscopy in patients with prior bariatric Roux-en-Y gastric bypass surgery. Surg Endosc. 2013 Aug;27(8):2894-9.

42. Ali MF, Modayil R, Gurram KC, Brathwaite CEM, Friedel D, Stavropoulos SN. Spiral enteroscopy-assisted ERCP in bariatric-length Roux-en-Y anatomy: a large single-center series and review of the literature (with video). Gastrointest Endosc. 2018 May;87(5):12417.

43. Zouhairi ME, Watson JB, Desai SV, Swartz DK, Castillo-Roth A, Haque M, et al. Rotational assisted endoscopic retrograde cholangiopancreatography in patients with reconstructive gastrointestinal surgical anatomy. World J Gastrointest Endosc. 2015 Mar 16;7(3):278-82. 